\title{
Ankylosing spondylitis without B27: no evidence for gene conversion
}

\author{
C T PEASE, ${ }^{1}$ S A ELLIS, ${ }^{2}$ A J McMICHAEL, ${ }^{2}$ AND D A BREWERTON ${ }^{1}$ \\ From the ${ }^{1}$ Department of Rheumatology, Westminster Hospital, London; and the ${ }^{2}$ Nuffield Department of \\ Clinical Medicine, John Radcliffe Hospital, Oxford
}

SUMMARY Isoelectric focusing gel electrophoresis was used to look for variant HLA molecules in five patients with HLA-B27 negative ankylosing spondylitis (AS). The isoelectric points of the HLA-A and B antigens from these patients and HLA paired controls were identical. This implies that the HLA-A and B antigens from the patients with AS and the controls are similar. Gene conversion of a nucleotide sequence from a B27 positive gene is thus unlikely to be the explanation for the existence of AS in patients who are HLA-B27 negative by alloantisera typing.

The strength of the association of HLA-B27 with ankylosing spondylitis (AS) in populations throughout the world strongly suggests a direct role for B27 in the aetiology of AS. ${ }^{1}$ Patients with AS who are HLA-B27 negative by routine alloantisera typing are likely to have another genetic factor of importance which is instrumental in the aetiology of their disease.

The alloantisera in routine use define HLA-B27 as a single antigen. Heterogeneity of this antigen was first demonstrated by Grumet and Fendly using two dimensional polyacrylamide gel electrophoresis to differentiate variants of B27 with different isoelectric points. ${ }^{2}$ Breuning et al reported that cytotoxic $T$ lymphocytes were able to detect subtypes of HLA-B27, ${ }^{3}$ and, subsequently, the same group showed that the HLA-B27 subtypes also had different isoelectric points, a result which they attributed to differences in the polypeptide backbone of the heavy chain. ${ }^{4}$ So far, the development of AS has not been restricted to a particular variant of B27. 56

Approximately half of all patients with AS who are B27 negative have or will develop psoriasis vulgaris or inflammatory bowel disease, ${ }^{7}$ implying that genes for these diseases may also predispose to AS. This leaves many cases of AS without B27, however, who are not associated with skin or bowel disease. An explanation not previously investigated is gene conversion. ${ }^{8}$ This is a mechanism put forward to explain the appearance within a

Accepted for publication 9 June 1988.

Correspondence to Dr C T Pease, Department of Rheumatology, Charing Cross Hospital, Fulham Palace Road, London W6 8RF. particular gene of short nucleotide sequences that seem to be derived from a gene at another locus. Our hypothesis is that a critical part of the B27 gene may be inserted into other alleles and be expressed. This may permit class I protein to function as B27 in, for instance, antigen presentation to $T$ cells. If present, it may be possible to determine such gene conversion by one dimensional isoelectric focusing gel electrophoresis. To test this possibility immunoprecipitated class I HLA antigens from patients with AS without B27 and from matched HLA identical controls were focused side by side to establish whether they had the same isoelectric points.

\section{Patients and methods}

PATIENTS

Five patients with AS (four male, one female) without B27 and with no clinical evidence of psoriasis or intlammatory bowel disease were selected. The HLA antigens detected in the patients by routine alloantisera testing were matched in healthy control subjects. Table 1 records the individual tissue types.

Table 1 HLA typing results for patients with ankylosing spondylitis

\begin{tabular}{llc}
\hline Patient No & HLA-A locus & $H L A-B$ locus \\
\hline 1 & 3 & 8,7 \\
2 & 2,32 & 21,5 \\
3 & 2,10 & 12,8 \\
4 & 1,33 & 7,8 \\
5 & 2 & 15,12 \\
\hline
\end{tabular}




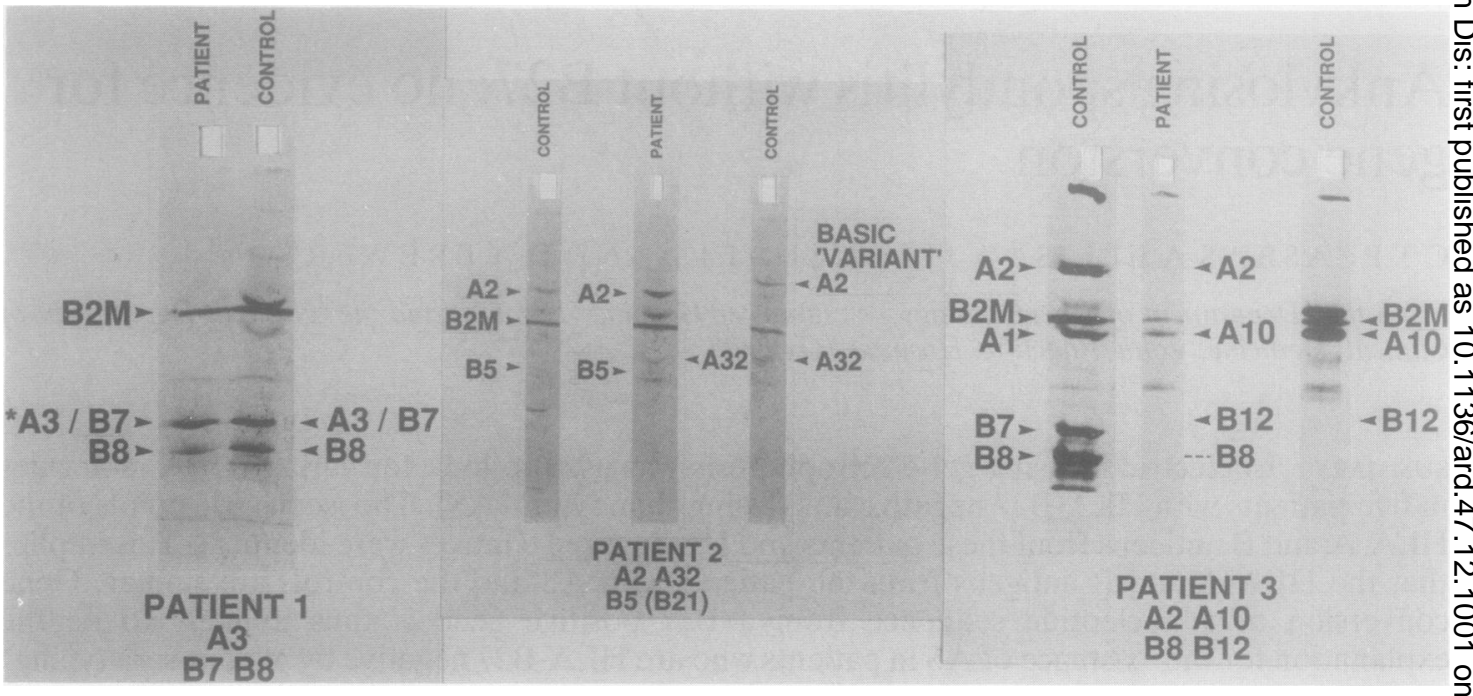

Fig. 1 Isoelectric focusing gel patterns of $\left[{ }^{35}\right.$ SImethionine labelled HLA-A and B antigens from three patients with $\vec{\square}$ ankylosing spondylitis and $H L A$ paired controls.

\section{METHODS}

Lymphocytes were metabolically labelled by incubation with $\left[{ }^{35}\right.$ S]methionine for 16 hours $(100$ $\mathrm{ml} / 5 \times 10^{6}$ cells). Cells were washed twice in phosphate buffered saline, then lysed in $0.5 \mathrm{ml}$ of 50 $\mathrm{mM}$ trometamol (TRIS), $5 \mathrm{mM} \mathrm{MgCl}, 0 \cdot 1 \mathrm{mM}$ phenylmethanesulphonyl fluoride, $0 \cdot 5 \%$ Nonidet P-40. Lysates were precleared before immunoprecipitation by incubation for one hour with $10 \mu \mathrm{g}$ of rabbit antimouse immunoglobulin followed by $50 \mu \mathrm{l}$ of $10 \%$ formalin fixed Staphylococcus aureus Cowan strain 1 (SAC). W6/32 ascites $(5 \mu \mathrm{g})$ was added and incubation at $4^{\circ} \mathrm{C}$ was continued for a further hour, followed by addition of $50 \mu$ l of SAC. ${ }^{9}$ After a further hour the SAC was pelleted and washed three times with lysis buffer. SAC bound immunoprecipitates were treated with neuraminidase before elution, by incubation at $50^{\circ} \mathrm{C}$ for 30 minutes in $9 \mathrm{M}$ urea, $2 \%$ Nonidet $\mathrm{P}-40,2 \%$ ampholines, 5\% 2-mercaptoethanol. For isoelectric focusing in slab gels the method of van der Poel et al was followed. ${ }^{10}$ The gels had a $\mathrm{pH}$ gradient of approximately 4-7, were focused for 16 hours, then dried and autoradiographed. Exact experimental details have been described previously. ${ }^{11}$

\section{Results}

Figure 1 shows the isoelectric focusing gel patterns of $\left[{ }^{35}\right.$ S]methionine labelled HLA-A and B antigens from three patients with $A S$ and from control subjects.
The isoelectric points for the corresponding HLA antigens are identical. Similar results were obtaing $\mathrm{d}_{\overrightarrow{0}}$ for the other two patients with AS. The HLA antigens matched with control subjects were $\mathrm{A} 1, \overline{\mathrm{Q}}$ $3,10,32,33$ and $\mathrm{B} 5,7,8,12,15$, and 21 .

\section{Discussion}

One dimensional isoelectric focusing gel electro- $\stackrel{\mathbb{2}}{-}$ phoresis is sufficiently sensitive to detect variantō HLA molecules that differ in only three to four amino acids. ${ }^{4}$ As the isoelectric points of the HLA$A$ and $B$ antigens in the patients and controls were identical there was no evidence that gene conversion represents an alternative mechanism for the development of spondylitis in the absence of B27 3 . We, therefore, consider it unlikely that there is insertion of a section of B27 into one of the HLA class I genes in these patients.

\section{References}

1 Brewerton D A. A reappraisal of rheumatic diseases and immunogenetics. Lancet 1984; ii: 799-802.

2 Grumet F C, Fendly B M, Fish L, Foung S, Engleman E G. 요 Monoclonal antibody (B27M2) subdividing HLA-B27. Hum Immunol 1982; 5: 61-72.

3 Breuning M H, Lucas C J, Breur B S, et al. Subtypes of HLAB27 detected by cytotoxic $T$ lymphocytes and their role in self recognition. Hum Immunol 1982; 5: 259-68.

4 Molders $\mathrm{H} \mathrm{H}$, Breuning $\mathrm{M}$ H, Ivanyi $\mathrm{P}$, Ploegh $\mathrm{H} \mathrm{L} . \stackrel{?}{+}$ Biochemical analysis of variant HLA-B27 antigens. Hum 7 Immunol 1983; 6: 111-7.

5 Karr R W, Hahn Y, Schwartz B D. Structural identity of humand 
histocompatibility leukocyte antigen-B27 molecules from patients with ankylosing spondylitis and normal individuals. $J$ Clin Invest 1982; 69: 443-50.

6 Trapani J A, Walker I D, McKenzie I F C. Two dimensional gel analysis demonstrates no structural alteration of HLA-B27 polypeptides between patients with ankylosing spondylitis and healthy individuals. Ann Rheum Dis 1984; 43: 177-80.

7 Brewerton D A. Inherited susceptibility to rheumatic disease. $J$ $R$ Soc Med 1978; 71: 331-8.

8 Klein J. Gene conversion in MHC genes. Transplantation 1984; 38: $327-9$.
9 Barnstable C J, Bodmer W F. Brown G, Galfre G. Milstein C, Williams A F. Production of monoclonal antibodies to group A erythrocytes. HLA and other human cell surface antigens. Cell 1978: 14: 9-15.

10 van der Poel J J, Mölders H, Thompson A, Plocgh H L. Definition of four HLA-A2 subtypes by CML typing and biochemical analysis. Immunogenetics 1983; 17: 609-21.

11 Ellis S A. Sargent I L, Redman C W G, McMichael A J. Evidence for a novel HLA antigen found on human extravillous trophoblast and a choriocarcinoma cell line. Immunology 1986; 59: $595-601$. 